\title{
PARTICLE SIZE REDUCTION OF ACECLOFENAC BY USING SURFACTANTS AND MICRONIZATION FOR NANOCARRIER ENTRAPMENT
}

\author{
*Kaur Jaspreet ${ }^{1}$, Singh Gurpreet ${ }^{1}$, Saini Seema ${ }^{1}$, Rana AC ${ }^{2}$ \\ ${ }^{1}$ Department of Pharmaceutics, Rayat Institute of Pharmacy, Railmajra, Punjab, India \\ ${ }^{2}$ Department of Pharmacology, Rayat Institute of Pharmacy, Railmajra, Punjab, India \\ Corresponding Author's E-mail: saini.jaspreet08@yahoo.com
}

Received 04 August 2012; Review Completed 08 Sep 2012; Accepted 11 Sep 2012, Available online 15 Sep 2012

\begin{abstract}
The Aceclofenac (2-[(2, 6- dichlorophenyl) amine] phenylacetoxyacetic acid) is a Non-Steroidal Anti-Inflammatory category of drug, which is water insoluble drug of BCS class-II which has low solubility and high permeability phenomenon. The particle size reduction technique is used to solubilize the aceclofenac. The particle size of aceclofenac in bulk form is 140-200 microns. In this experiment, The 35 microns particle size was reduced in powder form from 140-200 microns by using Air jet mill and 17.08 microns size was reduced by using dynomill and 33.62 microns particle size was reduced by using Tween 80 as surfactant as considered as lowest particle size. The Labrasol and $\mathrm{Na}$. CMC were also used in this experiment. The equipments used to reduce particle size of aceclofenac are ultra-Turrax (Ultra-sonication), Air jet mill and Dynomill. These all instruments used to reduce the particle size of aceclofenac are safe and not any chemical compound was added in any of the method described above. This study was used to see the uniform nature of the nano- and micro-particles entrapping the aceclofenac drug obtained by High shear homogenization, high pressure homogenization, Solvent-Diffusion evaporation and membrane contactor methods. If the particle size of aceclofenac cannot be reduced less than 14 microns then at the time of Permeation studies the same particle size will enter in Stratum corneum of Skin and entrapped in the carrier matrix. And formation of microns sized particles will obtained while preparing Solid lipid nanoparticles.

Keywords: Solubilization, Particle size reduction, Air jet mill, high shear homogenizer, particle size analyzer, Dynomill
\end{abstract}

Abbreviations: BCS shows Biopharmaceutical classification system, D.M.: Demineralised water, HSH: High speed homogenizer, Na. CMC: Sodium carboxy methyl cellulose, ACS: Aceclofenac solubility, I.P.: Indian Pharmacopoeia

\section{INTRODUCTION}

The Aceclofenac (2-[(2, 6-dichlorophenyl) amine $]$ phenylacetoxyacetic acid) is an effective non-steroidal antiinflammatory drug (NSAID) of phenyl acetic acid group, which possesses remarkable anti-inflammatory, analgesic and antipyretic properties ${ }^{1}$. Aceclofenac appears to be particularly well-tolerated among the NSAIDs, with a lower incidence of Gastro-intestinal adverse effects ${ }^{2}$. Unfortunately, Aceclofenac has low water solubility i.e. $(0.058 \mathrm{mcg} / \mathrm{ml})$ leading to poor dissolution. The biopharmaceutical classification system (BCS) divides all drug candidates into four different groups, according to their solubility and permeability ${ }^{3}$. Aceclofenac is an example of BCS class II compound, ${ }^{4}$ Therefore, the improvement of aceclofenac is an important issue for enhancing its bioavailability and therapeutic efficacy. Several techniques are commonly used to improve dissolution and bioavailability of poorly water-soluble drugs, such as Salt formation, $\mathrm{pH}$ adjustment, complexation and prodrug. All these have use of chemicals for their activity ${ }^{5}$. Objective of this research is to reduce the particle size of Aceclofenac to nanometer size by using Air jet mill, high speed homogenization containing surfactants (Tween 80, Labrasol and Na. CMC) and Dynomill.

\section{MATERIALS}

The Aceclofenac was a sample purchased from Suyash Laboratories. The Tween 80 was purchased from SD fine, India and Labrasol was purchased from Gattefosse SAS.

\section{METHODS}

Particle Size of Aceclofenac-The particle size of Aceclofenac was analyzed by Sympatec Particle size analyzer of bulk powder size reduction of Aceclofenac.

1. The lowest Particle size of Aceclofenac powder after Air jet mill ${ }^{5}=$ the three cycles of Air jet mill to reduce bulk original sized particles. The three readings were obtained as $1^{\text {st }}$ cycle, $2^{\text {nd }}$ cycle, and $3^{\text {rd }}$ cycle. The average reading was taken as the minimum particle size can reduced after particle size reduction.

2. The Particle size of Aceclofenac in following Solvents-The $3 \mathrm{~g}$ drug was dispersed in $50 \mathrm{~g}$ D.M. Water, $0.1 \%$ Tween 80 was weighed and put in beaker. The stirring with high speed homogenization was done for $15 \mathrm{~min}$. with $2 \mathrm{~min}$. gap each at 13.500 rpm, where it was characterized with particle size. Then $100 \mathrm{ml}$ water was added, and the above solution was then divided into three parts. In $1^{\text {st }}$ part $0.1 \%$ Tween 80 was added and stirring with HSH was done for $10 \mathrm{~min}$. In the $2^{\text {nd }}$ part the $1 \%$ Labrasol was added and stirred with $\mathrm{HSH}$ for $10 \mathrm{~min}$. at $6.500 \mathrm{rpm}$. In the $3^{\text {rd }}$ part $10 \mathrm{ml}$ NaCMC was added and stirred for 10 min. with $\mathrm{HSH}$ at $6.500 \mathrm{rpm}$. Further stirring at high speed of 9500 for $10 \mathrm{~min}$. and 13.500 for $10 \mathrm{~min}$. The batches were coded as ACS-1.1, ACS-1.2, ACS-1.3 (where ACS denotes to Aceclofenac solubility) 


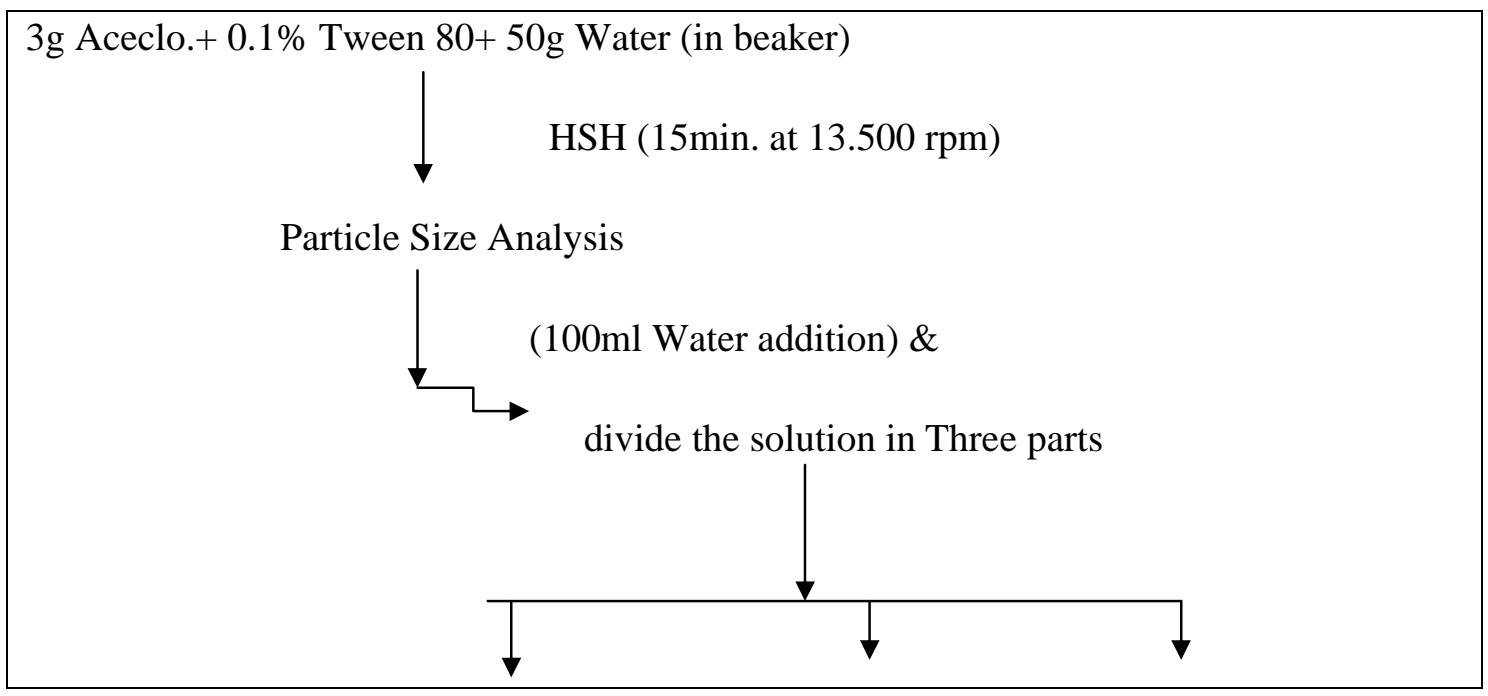

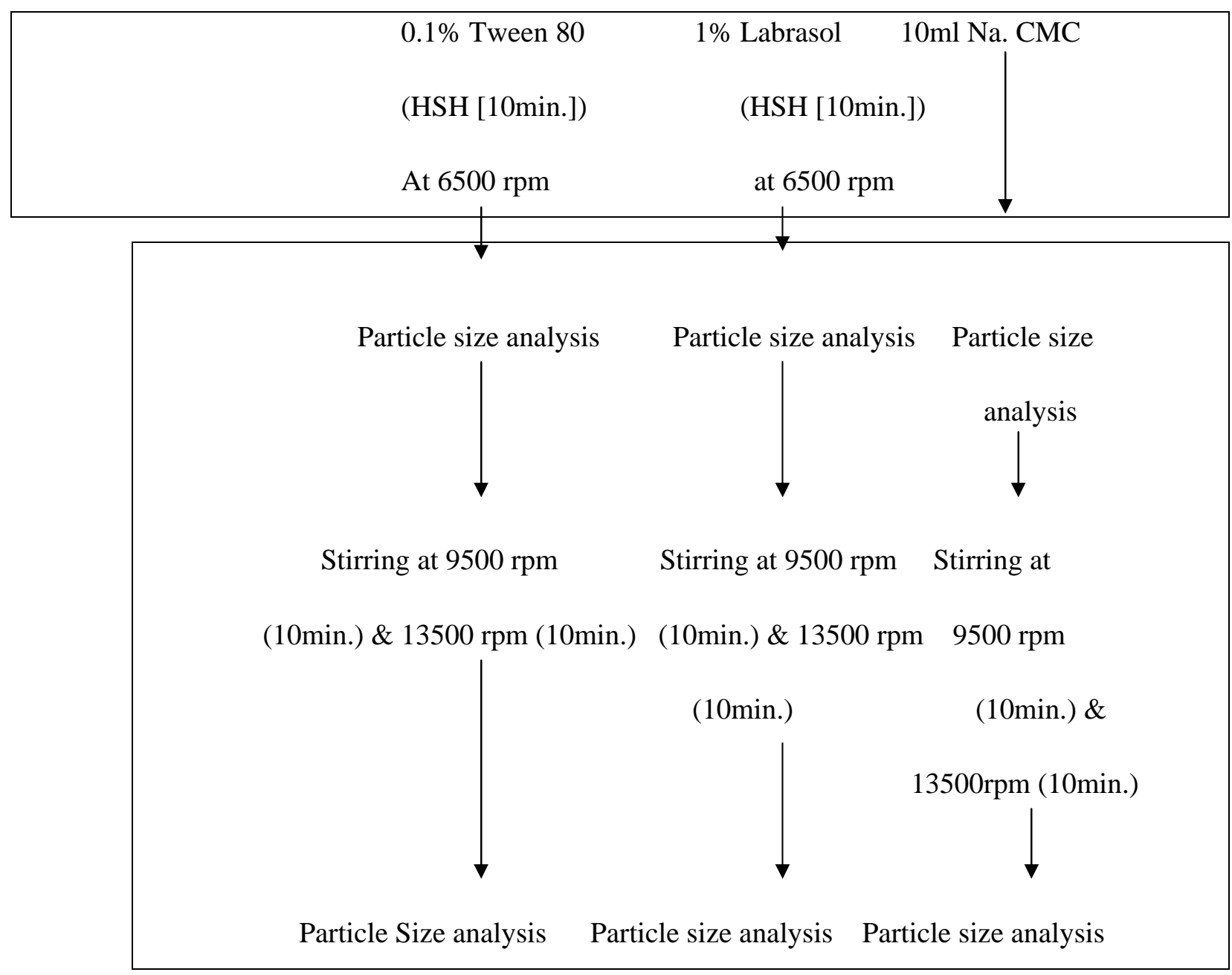

Figure 1: Flow chart of Processing of Particle size reduction by Surfactant mixture

3. Dynomill particle size reduction - The dynomill instrument was used to solubilize Aceclofenac in the water where tween 80 and $\mathrm{Na}$. CMC were added by the time 45 min. at $13.500 \mathrm{rpm}$ using zirconium beads of $0.2 \mathrm{~mm}$ dia. The batch was coded as ACS-1.4.

\section{RESULTS}

1. The Particle size of bulk Aceclofenac powder- 140200 microns

2. The lowest Particle size of Aceclofenac powder after Air jet mill $=$ the three cycles of Air jet mill to reduce 140ISSN: 2250-1177 
200 microns sized particles. The three readings were obtained as $1^{\text {st }}$ cycle, $2^{\text {nd }}$ cycle, and $3^{\text {rd }}$ cycle. The minimum size reduction in the Air jet mill of the Aceclofenac is 32 $\mu \mathrm{m}$.

Table 1: Showing Particle size

\begin{tabular}{|c|c|}
\hline Cycles & Particle Size $\left(\mathbf{X}_{\mathbf{9 0}}\right) \boldsymbol{\mu m}$ \\
\hline 1 & 37 \\
\hline 2 & 34 \\
\hline 3 & 33.6 \\
\hline 4 & 32 \\
\hline
\end{tabular}

Table: 2 Composition and particle size of Aceclofenac after solubilization with surfactants

\begin{tabular}{|l|l|l|l|}
\hline Composition & Batch & Solvents to dissolve drug & Particle size $\left(\mathbf{X}_{\mathbf{9 0}}\right) \boldsymbol{\mu m}$ \\
\hline Aceclofenac+Tween 80 & ACS-1.1 & Tween 80 & $58(1), 33.62(2)$ \\
\hline Aceclo.+Tween 80+Labrasol & ACS-1.2 & Labrasol & $60(1), 47.91(2)$ \\
\hline Aceclo.+Tween 80+Na CMC & ACS-1.3 & Na. CMC & $60(1), 36.81(2)$ \\
\hline Dynomill & ACS-1.4 & Tween 80, Labrasol, Na. CMC & 17.08 \\
\hline
\end{tabular}

Na. CMC: Sodium Carboxy-methylcellulose, (1) and (2) indicates the $1^{\text {st }}$ cycle and $2^{\text {nd }}$ cycle of the high speed homogenizer

Table: 3 Particle Size distributions of all batches for $\mathrm{X}_{10}, \mathrm{X}_{50}$, and $\mathrm{X}_{90}$

\begin{tabular}{|l|l|l|l|}
\hline Batch No. & $\mathbf{X}_{\mathbf{1 0}}(\mu \mathrm{m})$ & $\mathbf{X}_{\mathbf{5 0}}(\mu \mathrm{m})$ & $\mathbf{X}_{\mathbf{9 0}}(\mu \mathrm{m})$ \\
\hline ACS-1.1 & 2.27 & 13.41 & 33.62 \\
\hline ACS-1.2 & 7.72 & 27.01 & 47.91 \\
\hline ACS-1.3 & 2.78 & 15.27 & 36.81 \\
\hline ACS-1.4 & 4.48 & 10.6 & 17.08 \\
\hline
\end{tabular}

\section{DISCUSSION}

The minimum particle size of the Aceclofenac after dissolved in surfactant solution and micronization was found $17.08\left(\mathrm{X}_{90}\right) \mu \mathrm{m}$ by using dynomill. The Tween 80 (Batch 1.1) gives $33.62 \mu \mathrm{m}\left(\mathrm{X}_{90}\right)$, Labrasol (Batch 1.2) gives $47.91 \mu \mathrm{m}\left(\mathrm{X}_{90}\right)$ and Na. CMC (Batch 1.3) gives 36.81 $\mu \mathrm{m}\left(\mathrm{X}_{90}\right)$ particle sizes. By adding all the surfactants (Batch 1.4) and applying pressure by dynomill which are zirconium beads with $2 \mathrm{~mm}$ dia. So that Aceclofenac can be minimized till $17.08 \mu \mathrm{m}\left(\mathrm{X}_{90}\right)$ particle size as shown in Table 3. The Aceclofenac powder particle size is reduced from the $37 \mu \mathrm{m}, 34 \mu \mathrm{m}, 33 \mu \mathrm{m}$ and $32 \mu \mathrm{m}$ by $1^{\text {st }}$ cycle of

\section{REFERENCES}

1. IP, 2010

2. Gowda KV, Rajan DS, Mandal U, Selvan PS, Sam Solomon WD, Bose A, Sarkar AK, Pal TK, Chattaraz TK, Evaluation of Bioequivalence of two formulations containing $100 \mathrm{mg}$ of aceclofenac, Drug Dev. Ind. Pharm, 2006, 32, 19-25.

3. Gorden AL, Loebenberga R, Modern Bioavailability, bioequivalence and biopharmaceutics classification system, New scientific approaches to international regulatory standards, Eur. J. Pharm. Biopharm, 2000, 50, 3-12.

4. Lee B, Jung H, Enhanced bioavailability of poorly watersoluble aceclofenac using PEG-based solid dispersion in rats, beagle dogs and human subjects, AAPS Annual Meeting, New Orleans, LA, USA, Pharm. Sci. Suppl, 4, 1999, Pp, 14-18

5. Betz G, The role of drug solubility in formulation development, In: Rong Liu, ed. Water-insoluble Drug Formulation, CRC; Press Taylor and Francis Group, 2008, $615,19-9 \mathrm{c} 22$.
Air jet mill, $2^{\text {nd }}$ cycle of Air jet mill, $3^{\text {rd }}$ cycle of air jet mill and $4^{\text {th }}$ cycle of air jet mill as given in Table 1 . The particle size discussed in the Table 2 was based upon the first cycle and second cycle which were referring to (1) and (2) respectively. The addition of surfactants and increase in stirring time was there in the following cycles. The values of particle size analyzer in this are $58 \mu \mathrm{m}$ which is then reduced to the $33.62 \mu \mathrm{m}$ in ACS-1.1, the $60 \mu \mathrm{m}$ is reduced to $47.91 \mu \mathrm{m}$ in ACS-1.2, $60 \mu \mathrm{m}$ is then reduced to 36.81 $\mu \mathrm{m}$ in ACS-1.3. 